\title{
Indisciplina e Dispersão na Sala de Aula: Um desafio ao Educador Contemporâneo
}

Fabiana Araújo Nunes ${ }^{1}$

Resumo: Este artigo tem por objetivo analisar e refletir sobre a indisciplina e dispersão na sala aula, principais desafios que aflige a educação contemporânea. Trata-se de um estudo bibliográfico que aborda essa problemática. Assim, para esse momento se recorre aos estudos e pesquisa de diversos autores.Na educação contemporânea muito se fala em indisciplina e desmotivação na sala de aula, e isso nos leva a refletir sobre até que ponto a família e a escola vem desempenhando o seu papel, já que o aluno encontra-se cercado de estímulos novos, decorrente das novas tecnologias?

Palavras-Chave: Contemporaneidade. Indisciplina. Dispersão do aluno.

\section{Indiscipline and Dispersion in the Classroom: A Challenge to the Contemporary Educator}

\begin{abstract}
This article aims to analyze and reflect on the indiscipline and dispersion in the classroom, the main challenges that afflicts contemporary education. It is a bibliographic study that addresses this problem. Thus, for this moment, the studies and research of several authors are used.In contemporary education much is said about indiscipline and demotivation in the classroom, and this leads us to reflect on the extent to which the family and the school has been playing its role since the student is surrounded by new stimuli, resulting from new technologies?
\end{abstract}

Keywords: Contemporaneity. Indiscipline. Dispersion of the student.

\section{Introdução}

Este artigo tem como tema indisciplina e dispersão na sala de aula e pretende provocar uma discussão e uma reflexão acerca dos desafios enfrentados pelos educadores na contemporaneidade.

Sabe-se dos grandes desafios enfrentados pelas escolas no século XXI. São vários os fatores educacionais agregados à falta de interesse e desmotivação dos alunos, desvalorização dos professores, falta de participação da família, salas superlotadas, desordem e desrespeito, entre outros.

${ }^{1}$ Licenciada em Pedagogia, Especialista em Psicopedagogia Clínica e Institucional, Mestranda em educação Anne Sullivan. E-mail: professora_fabiana@ hotmail.com 
Atualmente, diante das transformações e avanços da sociedade, a escola encontra-se afetada e despreparada para atender as condições e anseios socioculturais dos alunos. Diante do fato, surge alguns questionamentos que deram embasamento teórico a pesquisa: Qual a função social da escola, hoje? Por que, mesmo diante das exigências de um país capitalista, os alunos encontram-se desmotivados para estudar? Será se a indisciplina na sala de aula é reflexo da convivência com os pais e com a sociedade? Diante desse quadro o que o professor tem feito para amenizar ou contornar essa realidade?

Partindo dessas questões se propõe com esse trabalho provocar uma discussão e uma reflexão acerca desses principais desafios que aflige a educação contemporânea. Trata-se de um estudo bibliográfico que aborda essa problemática. Assim, para esse momento, se recorre aos estudos e pesquisa de autores como: Chalita (2001), Freire (1998), Saviani (2005), entre outros.

Na educação contemporânea muito se fala em indisciplina e desmotivação na sala de aula, e isso nos leva a refletir que a família e a escola não vem desempenhando bem o seu papel, já que o aluno o aluno encontra mais razões pra está fora da escola, do que dentro.

\section{Função Social da Escola}

A escola tem uma função social complexa, diversificada e desafiadora, bem como extremamente importante na formação do indivíduo, como ser crítico e ativo, capaz de intervir nos problemas da sociedade.

Braz (2008, p. 14) complementa que:

[...] a escola, que é a instituição encarregada de formar cidadãos críticos, participativos, que sejam capazes de compreender a ideologia do mercado e que busquem a transformação, necessita discutir as novas relações sociais e de trabalho a fim de resgatar a sua importância social e política enquanto apoio à maioria da população que representa a classe trabalhadora.

Saviani (2005, p. 80) assegura que "o povo precisa da escola para ter acesso ao saber erudito, ao saber sistematizado e, em consequência, para expressar de forma elaborada os conteúdos da cultura popular que correspondem aos seus interesses". 
Id on Line Revista Multidisciplinar e de Psicologia

Id on Line Multidisciplinary and Psycology Journal

Diante das mudanças e avanços tecnológicos, a escola vem sendo fortemente afetada, e isso causa preocupação. Pois sabe-se que a escola é a porta de esperança, porta de entrada pra a transformação de muitas crianças, adolescentes e jovens. Segundo Masetto (1997, p.21) a escola surge historicamente como fruto da necessidade de preservar e reproduzir a cultura e os conhecimentos da humanidade, crença, valores e conquistas sociais, concepções de vida e de mundo.

A escola da sociedade contemporânea tem buscado constantemente se organizar para desempenhar melhor sua função social. Na contemporaneidade deve-se buscar inovações pedagógicas, valorização e respeito à cultura do aluno, privilegiando um ensino que garanta o desenvolvimento intelectual, social e cultural do aluno, valorização dos profissionais da educação, articulação e mediação entre a escola, família e comunidade; garantindo a formação de sujeitos críticos e participativos, aptos ao mercado de trabalho e a intervir nos problemas sociais

Infelizmente, é uma realidade constante na maioria das escolas, salas superlotadas e sucessivamente professores estressadas e alunos agitados

\section{A Indisciplina na Sala de Aula}

Os professores deparam-se cada vez mais com situações assustadoras de indisciplinas na sala de aula. São inúmeros os casos de indisciplinas na sala de aula, manifestada pela falta de limite dos alunos, desordem, bagunça, tumulto, mau comportamento, desinteresse e desrespeito às figuras de autoridade da escola e também ao patrimônio escolar.

Diante de alunos indisciplinados é comum que o professor entre em desespero, mas não é o melhor caminho. Lidar com a indisciplina é muito delicado e exige muito cuidado e sensibilidade, já que aluno indisciplinado não está acostumado com regras. Dessa forma, conforme sugere Parrat-Dayan (2008, p. 64), “[...] é mais eficaz se aproximar calmamente de um aluno e pedir para retomar seu trabalho que chamar a sua atenção em voz alta na frente de todos. $[\ldots] ”$.

O professor precisa ter disponibilidade para com o aluno. Embora, não seja fácil, porém é necessário; Talvez aquele aluno que faz bagunça, só queira chamar a atenção do professor ou 
Id on Line Revista Multidisciplinar e de Psicologia

Id on Line Multidisciplinary and Psycology Journal

externar alguma dificuldade que está vivenciando. Conforme Oliveira (2005, p. 65), se o professor souber ouvir o aluno sobre suas dificuldades, pessoais ou escolares, já favorecerá em muito o relacionamento e o clima de sala de aula.

Sabe-se que atualmente os padrões de família e sociedade mudaram e isso tem refletido de forma negativa na vida das crianças e adolescentes. Além da indisciplina ser um dos maiores problemas da sala de aula, ela interfere na aprendizagem dos alunos e influencia para que os professores se estressem e até adoeçam.

Os pais altamente permissivos e a sociedade moderna, onde tudo pode, tem causado grandes estragos na vida dos filhos, pois a indisciplina está associada a um conjunto de fatores, mas sobretudo, retrata a má educação dos pais.

É comum acreditarem que na escola estejam presentes as soluções para todos os problemas que venham surgir. Muitas vezes, os pais depositam toda a responsabilidade de educar somente na escola, deixando de exercer o seu papel.

E a escola, como sempre, abraça esse desafio de disciplinar os alunos. Com cuidado e atividades de intervenção, socialização e interação, como por exemplo: acordos de convivência, combinados de sala de aula e jogos com regras impostas; pode ajudar, a médio e longo prazo, a superar esse desafio. Não é fácil, porém é necessário!

\section{Desmotivação dos Alunos}

A desmotivação dos alunos é mais um dos grandes desafios enfrentados pelos professores, atualmente. É uma necessidade urgente estimular os alunos a sentir prazer pelos estudos, pois sabemos que numa turma de alunos uma minoria, tem esse estímulo, principalmente nas escolas públicas.

Ser um(a) aluno(a) motivado(a) é ter interesse em ir à escola, querer aprender os conteúdos e participar ativamente das atividades propostas pelo professor.

A desmotivação e falta de perspectiva dos alunos é um fator preocupante. É muito grande o índice de desmotivação dos alunos, hoje. Geralmente o aluno não tem interesse ou não consegue encontrar sentido para se dedicar às aulas. São vários os fatores que contribuem com a desmotivação dos alunos, como: características próprias do aluno, o ambiente escolar, a 
didática, metodologia e recursos de ensino utilizados pelo professor, relação professor/aluno, processo avaliativo, enfim, são vários.

E mais uma vez recai sobre o educador toda a responsabilidade de reverter o quadro, pois sabe-se que fora da escola o aluno tem acesso a uma gama de atrativos, que desperta prazeres no aluno, como: sociedade, mídias, redes sociais. Dessa forma, é natural que o aluno anseie por um ensino que desperte-lhe prazer, onde ele se sinta acolhido e possa interagir. Cabe ao educador refletir, avaliar e aprimorar constantemente sua prática. É importante observar os seguintes critérios:

Seja um professor protagonista e demonstre entusiasmo, amor e motivação pelo seu trabalho;

Elabore suas aulas com carinho, a ponto de levar pra seus alunos uma aula que os envolva, adequando-se aos anseios destes;

$>$ Estabeleça um acordo de convivência, elaborado e discutido juntamente com a turma;

Acolha bem a turma;

$>$ Apresente o plano de aula;

$>$ Promova um ensino contextualizado, relacionando o conteúdo ao contexto do aluno na sala de aula;

Promova a participação e interação dos alunos;

\section{O Papel Professor}

O professor é o principal agente de transformação social, é um semeador de sonhos, de ideias e de esperança, é o profissional mais importante da sociedade. Pois é ele que acompanha e orienta desde o primeiro rabisco.

Professor, eis um profissional de tão nobre missão, o único responsável por formar outros profissionais, como: empresários, engenheiros, médicos, políticos, advogados, profissionais que são mais bem pagos e valorizados do que o próprio professor.

Embora seja um profissional tão importante, o professor tem sido desde muito tempo, responsável por muitos insucessos escolares, o foco tem recaído sempre sobre os professores. 
Dessa forma, mesmo diante de tantas adversidades, cabe ao professor decidir entre ser vítima ou protagonista da sua história. O professor protagonista sonda o problema, reflete, avalia e busca intervenções e soluções; já o professor vítima, só consegue enxergar o problema e apontar culpados, não vislumbra intervenção, nem tão pouco, solução. (CARVALHO; OLIVERA, e CARITA, 2016).

Lembrando que a postura do professor reflete na vida do aluno de forma positiva ou negativa. É impossível que um professor desmotivado consiga motivar e estimular um aluno.

O professor precisa está preparado para lidar com esses novos alunos e isso se torna desafiador. A função do professor hoje, não e apenas de ensinar, mas a de propiciar ao aluno a construção do conhecimento, e o ensino deve ser contextualizado. Para Moran "aprendemos melhor quando vivenciamos, experimentamos, sentimos." (MORAN, 2008, p. 23).

As escolas estão vivendo momentos de transição, e estas precisam se reelaborar, adequando-se ao novo aluno e também a nova formação do corpo docente. Essas mudanças são irreversíveis, e estão relacionadas ao desenvolvimento das tecnologias de informações e comunicação. São ferramentas que possibilitam ao professor desenvolver novas práticas pedagógica.

A educação vai além de fornecer pessoas qualificadas ao mercado de trabalho, ela permite desenvolver talentos e formar cidadãos críticos capazes de intervir na sociedade. Só uma educação de qualidade, capaz de aguçar o pensamento crítico e reflexão do aluno poderá possibilitar a transformação da sociedade.

Entende-se que a esperança de um mundo mais justo e menos corrupto está na educação, através da conscientização e da livre expressão.

O professor da atualidade é desafiado a refletir e avaliar constantemente a sua prática, visando aperfeiçoar e reelaborar a sua prática para se tornar um profissional melhor. Nesse sentido, conta-se com a importante contribuição de FREIRE, 1998:

[...] na formação permanente dos professores, o momento fundamental é o da reflexão crítica sobre a prática. É pensando criticamente a prática de hoje ou de ontem que se pode melhorar a próxima prática [...]. (FREIRE, 1998, p.43-44).

\section{O Papel da Família}


A família e a escola devem andar juntas para se complementarem na educação dos filhos. Os pais são como referenciais na vida dos filhos, dessa forma, devem ocupar o seu lugar na vida destes e desempenhar o seu papel, pois a educação dos filhos não deve ser delegada apenas a escola. Sabe-se o quanto tem se tornado difícil impor limites e agregar valores na vida dos filhos nos dias atuais, no entanto, os pais precisam elegê-los como prioridades, não dá pra adiar uma boa relação e diálogo com estes, pois esta se traduz como uma obrigação permanente.

Segundo Chalita (2001 p. 20), a família tem a responsabilidade de: “formar o caráter, de educar para os desafios da vida, de perpetuar valores éticos e morais. A família é um espaço em que as máscaras devem dar lugar à face transparente, sem disfarces. O diálogo não tem preço".

A família ocupa um lugar especial e insubstituível na vida da criança, quando a família não tem uma boa convivência e não dar bons exemplos, isso irá refletir na vida da criança de forma negativa, causando transtornos, agressividade, dificuldades de aprendizagem, entre outros. A criança reflete o que vive em casa, afinal a família é o maior referencial na vida da criança.

O grande vilão da indisciplina na sala de aula hoje é reflexo da má atuação dos pais na imposição de limites e regras vida das crianças.

Acredita-se que se todos os pais tivessem consciência da importância de sua atuação na educação dos seus filhos, os mesmos teriam uma participação mais significativa e as escolas teriam melhores resultados.

\begin{abstract}
Os pais de hoje em dia acham que vão compensar a ausência comprando brinquedos, mas o que a criança precisa é que o pai olhe para ela e veja do que ela precisa, que é da presença, que ele participe da vida dela, interaja, leia junto uma historinha, construa um castelo na areia da praia. É preciso um entendimento melhor de valores e criança precisa de carinho e não do brinquedo mais caro, que vai ser só mais um para acumular" (In: http://www.tribunahoje.com/noticia/135480/cidades/2015 /03/18/usoexcessivo-de-tecnologia-pode-afetar-saude-de-criancas.html)
\end{abstract}

A escola sozinha não cumpre o papel de educar. A escola recebe alunos com níveis de comportamentos diferentes e consequentemente com ritmos de aprendizagem diferentes. Os fatores sociais, afetivos e emocionais influenciam o desenvolvimento cognitivo da criança, de forma positiva ou negativa, dependendo dos estímulos que ela recebe. E por isso, a escola 
precisa conhecer a realidade social e cultural desse aluno e os fatores que dificultam a aprendizagem, para poder intervir.

O ideal é que desde cedo, tanto a família quanto a escola criam uma rotina na vida das crianças, para que desde cedo os pequenos entendam que na vida existem rotinas que facilitam e organizam as suas ações.

\section{Considerações Finais}

Conclui-se que a educação hoje se depara com grandes desafios, dentre eles destaca-se a indisciplina na sala de aula e a dispersão do aluno aliado à desestrutura familiar e o despreparo escolar.

Diante desse cenário, a escola necessita inovar e reformar seu sistema de ensino, visando atender os anseios e necessidades do aluno do século XXI. É necessário uma escola que motiva, que valoriza o conhecimento do aluno, onde ele se sinta bem; pois todo aluno tem potencial, basta explorá-lo. E sobretudo, uma escola que estabeleça uma boa parceria com a família no intuito de orientá-la a exercer melhor o seu papel.

Faz-se necessário uma análise reflexiva uma discussão e uma tomada de decisão urgente acerca da problemática da indisciplina e da desmotivação dos alunos nos dias atuais, bem como fortalecimento de vínculos entre família e escola, e a valorização e apoio ao trabalho do professor.

Enfim, espera-se que as políticas públicas para melhorar a qualidade da educação sejam efetivadas, reelaboradas, discutidas, aprofundadas, reinventadas e de preferência bem sucedidas no cenário educacional.

\section{Referências}

BRAZ, Maria Regina. Reflexões e alternativas Pedagógicas para o enfrentamento da indisciplina em sala de aula. (Material Didático produzido no segundo período do PDE Turma 2009). 
Id on Line Revista Multidisciplinar e de Psicoloqia

Id on Line Multidisciplinary and Psycology Journal

CARVALHO, Maria das Graças de; OLIVERA, Gislene F. de, CARITA, Ana. Representações da Violência por Professores. Id on Line Revista de Psicologia, Fevereiro, vol.10, n.29. p. 0722, 2016.

CHALITA, Gabriel. Educação: A solução está no afeto. São Paulo: Editora Gente, 2001.

FREIRE, P. Pedagogia da autonomia: saberes necessários à prática educativa. $8^{\mathrm{a}}$ Ed. Rio de Janeiro: Paz e Terra, 1998. (Coleção Leitura).

MAGALHÃES, Thayanne. Uso excessivo de tecnologia pode afetar saúde de crianças. Tribuna Independente: Março, 2015. Disponível em http://www.tribunahoje.com/noticia/135480/cidades/2015/03/18/uso-excessivo-de-tecnologiapode-afetar-saude-de-criancas.html. Acesso em 05 de janeiro de 2017.

MASETTO, Marcos. Didática: a aula como centro- São Paulo:FTD,1997.

MORAN, José Manuel; MASETTO, Marcos T.; BEHRENS, Marilda Aparecida. Novas tecnologias e mediação pedagógica. 14ª Ed. Campinas, SP. Papirus, 2008.

SAVIANI, Demerval. Pedagogia histórico-crítica: Primeiras aproximações. Campinas, SP: Autores Associados, 2005.

OLIVEIRA, Maria Isete de. Indisciplina escolar: Determinantes, conseqüências e ações. Brasília: Líber Livro, 2005.

PARRAT-DAYAN, Silvia. Trad. Silvia Beatriz Adoue e Augusto Juncal - Como enfrentar a indisciplina na escola. São Paulo: Contexto, 2008.

Como citar este artigo (Formato ABNT):

NUNES, Fabiana A. Indisciplina e dispersão na sala de aula: um desafio ao educador contemporâneo. Id on Line Revista Multidisciplinar e de Psicologia, Janeiro de 2017, vol.10, n.34, p. 77-85. ISSN: 1981-1179.

Recebido: 16.01.2017

Aceito: 01.02.2017 